\title{
Угрозы и вызовы многополярного мира: укра- инский кризис в качестве конкретного примера
}

\section{Олексий Ицхак}

Национальный институт стратегических исследований (НИСИ), Днепропетровск, Украина, http://www.niss.gov.ua/

\begin{abstract}
Резюме: По мере того, как однополюсная система после Холодной войны трансформировалась в полицентрическую, она становилась все более сложной и менее предсказуемой. Для того, чтобы разрушить новую систему, нужно меньше усилий, чем для того, чтобы она развивалась дальше. Полицентрическая международная система с самого своего появления подвержена гибридным угрозам. Их трудно обнаруживать и прогнозировать. Россия первая начала эксплуатировать новые уязвимые стороны системы для получения односторонних выгод. Гибридная война России против Украины была всего лишь начальным эпизодом в ее более масштабной попытке разрушить весь мировой порядок. Ответственные мировые силы должны или устранить эти уязвимости полицентрического мира, или заблокировать злонамеренные попытки их использовать.
\end{abstract}

Ключевые слова: многополярный мир, полицентрический мир, гибридная война, украинский кризис, российская политика.

\section{Введение}

Кризис в самой Украине и вокруг нее ясно показал, что мир изменился. Это не является новостью для большинства знакомых с ситуацией политиков и исследователей. Изменения накапливались медленно, и большая часть последствий была предсказуемой. Однако, до недавнего времени наше видение мира вписывалось в общее мышление эпохи после Холодной войны. Это уже не мир двух сверхсил, но и не мир с одним центром тяжести, а также и не многополярный мир, это мир, застывший во времени, где-то на середине перехода. И в этот момент Россия решила предъявить 
Украине ряд требований таким образом, как будто направила большую стрелку в прошлое. По словам русского аналитика Лилии Шевцовой, российский президент Владимир Путин прикончил глобальное «междуцарствие». ${ }^{1}$

\section{Полюсы в свободном от полюсов мире}

Основная идея нового мира, который появился на наших глазах, возможно, наиболее ярко была сформулирована пять лет тому назад Ричардом Хаасом, который охарактеризовал новый мировой порядок как «неполярный». Несмотря на некоторое сходство с многополярностью, которая существовала до Первой мировой войны, сегодняшние центры могущества не являются "полюсами» в полном смысле слова, какими были когда-то самые большие государства в мире: «Государства сталкиваются с вызовами сверху, со стороны региональных и глобальных организаций; с вызовами снизу, со стороны милиций; и с вызовами сбоку, со стороны неправительственных организаций (НПО) и корпораций». ${ }^{2}$ Эту картину также называют «полицентрическим» миром. Наиболее полно это видение описано в работе «Глобальные тенденции 2030: граждане во взаимосвязанном и полицентрическом мире», ${ }^{3}$ в котором ключевые моменты совпадают с изложенными Хаасом.

Между тем, футурологи предсказывали технологическую революцию, которая фундаментальным образом изменит мир, но это, видимо, будет не скоро. 3D принтирование должно еще возобладать над промышленным производством, киберпространство не расширилось еще до степени, до которой могло бы, топливо еще не поставляется с других планет, медицина все еще бессильна перед многими смертельными болезнями, биотехнологии еще не завалили мир продовольствием, и нет никакого решения проблемы изменения климата. Тем не менее, уже есть представление, как все это случится в обозримом будущем.

Абстрагируясь от технологической революции, сейчас уже можно различить, как проглядываются приблизительные контуры полицентрического мира, раньше, чем ожидали теоретики, и это порождает дополнительные угрозы и вызовы. Многополярный мир, который предшествовал Первой мировой войне, и двухполюсный мир, который сформировался по-

1 Lilia Shevtsova, "Putin Ends the Interregnum," The American Interest, 28 August 2014, доступно на http://www.the-american-interest.com/shevtsova/2014/08/28/ putin-ends-the-interregnum (по состоянию на 31 августа 2014).

2 Richard N. Haass, "The Age of Nonpolarity," Foreign Affairs 87:3 (2008), доступно на www.foreignaffairs.com/articles/63397/richard-n-haass/the-age-of-nonpolarity (по состоянию на 31 августа 2014).

3 "Global Trends 2030: Citizens in an Interconnected and Polycentric World," European Strategy and Policy Analysis System (ESPAS) (European Union Institute for Security Studies, March 2012), доступно на http://www.iss.europa.eu/uploads/media/ ESPAS_report_01.pdf (по состоянию на 31 августа 2014). 
сле Второй мировой войны, были абсолютными в смысле, что поляризованные пространства вокруг каждого центра были в непосредственном соседстве с ним, с минимальными нейтральными зонами. Угрозы были предсказуемыми, и реакцию на них можно было вычислить рациональным образом. Их можно назвать традиционными угрозами. Крах двухполюсной системы после окончания Холодной войны превратила на короткое время мир в однополюсную систему. Однако, могущество американского полюса быстро потеряло свой абсолютный характер. Неожиданно появились новые и быстроразвивающиеся центры могущества, каждый из которых надеялся стать новым полюсом. В этом переходном периоде, в свою очередь, появились новые угрозы. Их список длинен, и он будет расширяться и дальше под влиянием множества граней глобализации. Некоторые из этих угроз учтены государствами и международными организациями, институциями и политикой в сфере безопасности. К примеру, Лиссабонский саммит НАТО в 2010 году перечислил терроризм, распространение ОМУ, кибератаки и природные бедствия как ключевые сферы его деятельности.

Традиционные и новые угрозы не исчезли с появлением полицентрического мира, но условия, в которых они проявляются, стали качественно различными. Пространства, которые были несильно структурированными вокруг полюсов, или вообще не были поляризованными, стали системным элементом. В таких пространствах есть центры притяжения разной массы, действия которых в отсутствии глобального менеджмента прибавляют динамичность глобальной системе. Сама концепция нового мирового порядка теперь имеет новое значение. Порядок существует как явление со своими внешними проявлениями и со своими внутренними законами, но он существует и как система рационального менеджмента. Образно говоря, это красочная флотилия из кораблей, лодок и плотов, которые связаны канатами разной прочности, и которая подхвачена почти невидимым морским течением, несущим ее к новым берегам или смертельным водоворотам. Никто не знает, как выбрать слабину канатов и как артикулировать взаимосвязи, чтобы флотилия стала управляемой и сознательно могла бы выбирать свой курс.

Возвращаясь к определению Хааса однополярного мира, можно сказать, что было бы полезным иметь более точное разделение, так как мир является «слегка полярным». Есть полюсы, но они не являются абсолютными, и они соперничают с центрами притяжения разной массы. Полюсы отличаются от центров в смысле степени концентрации влияния и могущества - экономического, политического, военного или идеологического. Есть множество центров разного типа, располагающих одними или другими ресурсами. Но только полюсы сочетают разные сферы могущества; они все еще идентичны государствам и группам государств.

Нельзя отрицать, что США, ЕС, Китай и Россия являются полюсами, но они не имеют абсолютного влияния. Корпорации, международные орга- 
низации, НПО и религиозные структуры - даже непризнанные государства - имеют свои сферы влияния и иногда, очевидно, надеются стать новыми полноправными полюсами. Сферы могущества и влияния, исходящие из разных полюсов, пересекаются и взаимосвязаны удивительным образом, превращая проблему глобального менеджмента в новый вызов для международной безопасности.

\section{Украинский кризис: западное измерение}

Спускаясь с вершин абстрактной теории к ситуации на полях сражения Восточной Украины, уже можно увидеть конкретные проявления некоторых аспектов полицентрического мира. На первый взгляд, украинский кризис попадает в уже известные категории: имеются сепаратизм, поддерживаемый из-за границы, и инструментарий «смены режима». Однако, более пристальный анализ раскрывает попытки России использовать слабости полицентрического мира, чтобы восстановить себя в качестве одного из полюсов. Это попытки, которые имеют глобальные последствия.

Концепция внешней политики России декларирует, что «международные отношения проходят через переходный период, природа которого состоит в формировании полицентрической международной системы». Формирование этой системы не считается данностью - это должно быть желаемое для России конечное состояние. Недавно российский министр иностранных дел Сергей Лавров заявил: «Является фактом то, что кризис на Украине есть одно из проявлений родильных мук, в которых рождается настоящий полицентрический мир». ${ }^{5}$ Согласно русской логике, Россия через свои действия в отношении Украины - помогает строительству полицентрического мира, тогда как Запад мешает этому с целью «искусственно замедлить появление этого многополярного и полицентрического мира, который является объективным результатом тенденций в мировом развитии».

Одержимость России идеей полицентрического мира проистекает из идеи, что при децентрализованном характере мира России легче будет реализовать свои амбиции в качестве полюса, наращивая свое могущество и

4 Министерство иностранных дел Российской Федерации, «Концепция внешней политики Российской Федерации», «Концепция внешней политики РФ, одобренная президентом РФ, В.В. Путиным 12 февраля 2013 года», доступно на www.mid.ru/brp_4.nsf/0/6D84DDEDEDBF7DA644257B160051BF7F (по состоянию на 31 августа 2014).

5 «Лавров: Украинский кризис, это родильная боль, в которой рождается полицентрический мир», Око планеты, 11 апреля 2014, доступно на http://okoplanet.su/politik/ politiklist/238618-lavrov-krizis-na-ukraine-odno-iz-proyavleniy-tehmuk-v-kotoryh-rozhdaetsya-policentrichnyy-mir.html (по состоянию на 31 августа 2014).

6 "US and EU hinder Russian actions in preventing global threats," FOCUS News Agency, 27 August 2014 (по состоянию на 31 августа 2014). 
свое влияние, даже если такое наращивание будет полито кровью, человеческими страданиями и экономическими потерями. Это есть негативное прочтение новых возможностей. На практическом уровне причина, обуславливающая действия России, была сформулирована в начале 2013 года Валерием Герасимовым, начальником генерального штаба, следующим образом:

В применяемых методах сопротивления ударение смещается на широкое использование политических, экономических, информационных, гуманитарных и других невоенных мер, применяемых в сочетании с протестным потенциалом населения. Все это дополняется скрытными военными методами, в том числе средствами информационной войны, и операциями сил специального назначения. Открытое использование силы часто предпринимается под прикрытием операций по поддержанию мира и урегулирования кризисов только на определенном этапе, обычно для обеспечения абсолютного успеха в конфликте.

Этот пассаж, часто цитируемый, интересен по ряду причин. Герасимов говорит об опыте Арабской весны, но из этого и других его заявлений видно, что он интерпретирует этот феномен в духе современных российских конспиративных теорий. Основной тезис состоит в том, что «цветные» революции и другие политические катаклизмы являются новой формой войны, которую ведут США и Запад в целом, в которой объектом нападения является Россия, с ее «конструктивным» политическим режимом и «сказочными» природными ресурсами.

В России, и не только среди руководства, но и в массовом сознании, конфликт с Украиной воспринимается как «справедливый» ответ на действия США. Некоторые из российских аргументов, возможно, заслуживали бы внимания, если бы не имело место следующее обстоятельство: образ действий России на Украине вызывал деградацию идеологии, политики и экономики на каждом новом этапе эскалации конфликта. Сначала в российском информационном пространстве продвигался тезис, что в Киеве к власти пришла «фашистская хунта». Это можно было бы назвать причудой информационной войны, если бы не масштаб пропаганды. Большинство российского населения, значительная часть населения оккупированного Крыма и восточных регионов Украины были убеждены, что в результате западных действий на Украине фашизм снова поднял свою страшную голову, и что Украина «перестала существовать» как государство, тогда как Россия имеет право использовать любые средства для нейтрализации угрозы. Демонизация чьего-либо врага не ново для истории западной прессы, но здесь важен размах пропаганды. Российское восприятие властей Украины сравнимо разве что с тем, как западное информационное

\footnotetext{
Валерий Герасимов, «Ценность науки состоит в возможности предсказывать. Новые угрозы требуют переосмысления способов и средств ведения войны», Военно-промышленный курьер, 27 февраля 2013, доступно на http://www.vpknews.ru/articles/14632 (по состоянию на 31 августа 2014).
} 
пространство реагировало бы на иностранный субъект, заслуживающий такую ненависть, как Гитлер, Милошевич, Хуссейн, Каддафи и Ким Чен-ын, все в одном лице, - и при этом было бы заявлено, что это чудовище было создано Россией.

«Успех» этой деструктивной информационной кампании и последующие шаги Росси, направленные на эскалацию конфликта, нельзя объяснить, как просто государственную монополию и жесткое, централизованное управление. Были широко использованы коммерческие пиар-агентства, а также общественные организации, финансовые и промышленные холдинги «патриотической ориентации». Военной частью операции по аннексии Крыма являлась работа так называемых «маленьких зеленых человечков», или "учтивых людей» (хорошо экипированных военнослужащих без знаков различия), которая была организована российским министерством обороны и силами специального назначения. Социальным и политическим элементом была нейтрализация проукраинских сил, «переключение» местного управления с Киева на Москву, организация референдума - все это было осуществлено с помощью организованных структур и финансов одной из главных российских финансовых и промышленных групп. Затем смешанная «ударная группа», включающая пиар-экспертов, политиков среднего уровня, администраторов и «спутников войны» - все усиленные ресурсами, отнятыми у Крыма, в том числе захваченное вооружение, - были направлены в Восточную Украину, ${ }^{8}$ после того, как регион был «подогрет» СМИ и флэш-мобами уличных бойцов (так называемая «Российская весна»). Когда «блицкриг» провалился, Россия была вынуждена прибегнуть к военной эскалации, которая к концу лета 2014 года привела к развертыванию регулярных российских войск, снова без знаков различия.

Хотя у России есть право, чтобы ее аргументы были услышаны, методы, которые она использует для доказательства их правомерности, подвергает ее логику сомнению. Представители Запада, знакомые с «Реалполитик» весьма справедливо обращают внимание на естественные рефлексы России в отношении расширения НАТО и ЕС и вестернизации ее соседей: «Представьте себе ярость Вашинтона, если бы Китай создал могучий военный союз и попытался бы включить в него Канаду и Мексику». ${ }^{9}$ Отсюда следует вывод, что Украина должна превратиться во вторую Финляндию для того, чтобы текущий кризис был разрешен, в том числе с учетом не

8 Олег Кашин, «От Крыма до Донбасса: приключения Игоря Стрелкова и Александра Бородая», Слон, 19 мая 2014, доступно на http://slon.ru/russia/iz_kryma_ v_donbass_priklyucheniya_igorya_strelkova_i_aleksandra_borodaya-1099696.xhtml (по состоянию на 31 августа 2014).

9 John J. Mearsheimer, "Why the Ukraine Crisis Is the West's Fault," Foreign Affairs 93:5 (2014), доступно на http://www.foreignaffairs.com/articles/141769/john-jmearsheimer/why-the-ukraine-crisis-is-the-wests-fault (по состоянию на 31 августа 2014). 
только военных, но и экономических и социальных аспектов вынужденного нейтралитета.

Эта идея стоила бы упоминания и могла бы найти резонанс на Украине, если бы не некоторые оговорки. До кризиса в отношениях с Россией, и даже на начальных стадиях его развития, никто серьезно не рассматривал членство в НАТО. Статус неприсоединившегося государства был заложен в законодательстве страны. В 2008 году НАТО отказало Украине в предоставлении ей Плана действий по членству (ПДЧ), что соответствовало действительным настроениям украинского общества и украинских элит. Идею членства поддерживало небольшое меньшинство (около 15\%) населения. Российская реакция на Соглашение об ассоциации Украины с ЕС достигла уровня истерии, и летом 2013 года - задолго до подписания - эта истерия привела к введению торговых санкций в качестве отголоска более ранней реакции в 2008 году на возможность выкладывания Пдч на стол. Тогда Россия заявила Украине, что если Украина откажется от членства в НАТО, она сможет развивать экономическое сотрудничество с ЕС одновременно с партнерством с Россией. Но когда этот вопрос достиг стадии практической реализации, оказалось, что в глазах России ЕС был «Содомом и Гоморрой», жадно плетущим заговоры с целью проглотить Украину, просто чтоб досадить России. Хотя многие считают это преувеличением, даже поверхностный просмотр российского информационного пространства показывает, что это скорее всего преуменьшение того, как российские интересы рационализируются в стране.

Опыт Украины показывает, что России никогда не хватает никаких уступок со стороны Украины, и не существует устойчивого статус-кво, который не лишил бы страну ее идентичности. Это и есть основная проблема в установлении солидных, дружеских отношений. Первые эпизоды «бряцания оружием» в отношении Украины имели место еще в 2000-х, когда администрация Президента Леонида Кучмы была весьма далека от какого бы то ни было сближения с НАТО и ЕС. Здесь уместно вспомнить, что Россия без предупреждения построила дамбу, связывающую ее территорию с украинском островом в Керченском проливе, где был расположен украинский пограничный пост, и впоследствии объяснила этот инцидент как «инициативу местных властей», и неожиданную дислокацию войск в крымском военном компаунде для проведения учений и преодоления технических затруднений без предварительного уведомления Украины. Потом Украина была склонна не замечать и пренебрегать такими инцидентами. Позже начались газовые войны против «оранжевого» правительства, которое делало громкие декларации насчет членства в НАТО и ЕС, хотя и не предпринимало конкретные шаги. Когда в 2010 году к власти пришел Виктор Янукович, начался кратковременный ренессанс благодаря односторонним уступкам Украины по гуманитарным, политическим и военным вопросам, в том числе декларации о статусе неприсоединения и продолжения договоров о найме баз для Черноморского флота. Однако, еще в 2011 году, за- 
долго до завершения переговоров о Соглашениях об ассоциации с EC, началось охлаждение, так как Россия обнаружила, что Украина не желает участвовать в “настоящей интеграции», которую Россия понимала, как образование единого государства. Торговая война 2013 года была последним этапом этого ухудшения. Это иллюстрирует представление, что Россия не была довольна превращением Украины во вторую Финляндию, независимо от политических намеков и посланий, которые она могла распространять через СМИ или дипломатические каналы. Россия могла терпеть Украину в качестве независимого государства только в том же статусе как у Беларуси, но не более. Само существование Украины воспринималось российской элитой как «геополитическая агрессия» Запада. Голда Меир отчеканила фразу, которая применима не только к Израилю, но и к сегодняшней Украине: «Мы хотим жить. Наши соседи хотят видеть нас мертвыми. Это не оставляет много места для компромисса». ${ }^{10}$

Возвращаясь в сферу теории, похоже, невозможно найти более масштабную попытку России позиционировать себя в качестве полюса путем использования уязвимости полицентрического мира, в данном случае в отношении Украины. В 2013 году Украина оказалась в отчаянном финансовом положении и приближалась к дефолту. Маневры администрации Януковича между ЕС и Россией были направлены на скорое получение иностранной помощи. По некоторым оценкам, Украина оказалась в такой ситуации из-за перемен на глобальных финансовых рынках, последовавших за изменением политики Федеральной Резервной Системы США. ${ }^{11} \mathrm{He}$ было злонамеренных планов, направленных против Украины - Украине просто не повезло. В результате украинские власти предприняли шаги, которые стали причиной острого внутреннего кризиса, который в 2014 году привел к общим политическим волнениям. Россия восприняла эти события как угрозу, но также и как возможность. В марте она аннексировала Крым, что позволило российским властям решить множество внутренних проблем, в том числе тотальную маргинализацию всей оппозиции и переориентирования социального недовольства на Украину. Даже если начальная оценка влияния действий Федеральной Резервной Системы вызывает сомнения, она иллюстрирует, как могут развиваться события в полицентрическом мире без глобального менеджмента.

Эти события подвигли Россию начать строить еще более амбициозные планы. Массовый характер заявлений и действий предполагает существование общего плана, который не был объявлен официально: запустить цепную реакцию, которая разорвет Украину (без использования военной

10 “Goldele Mabovich' dream," доступно на http://www.freie-juedische-meinung.de/ portraits/438-2013-05-02-19-17-17 (по состоянию на 31 августа 2014).

11 Gideon Rose and Benn Steil, "Foreign Affairs Focus: Benn Steil on Fed Policy," Foreign Affairs, 2 August 2014, доступно на www.foreignaffairs.com/discussions/audiovideo/foreign-affairs-focus-benn-steil-on-fed-policy (по состоянию на 31 августа 2014). 
силы, если возможно, и с ее использованием, если нужно), провоцирование схизмы в ЕС по украинскому вопросу, срыв планов создать зону свободной торговли между США и ЕС и изолирование США от европейского континента. Интересен арсенал использованных ресурсов с учетом масштаба и изобретательности его применения. Были привлечены очень могущественные и эффективные пропагандистские ресурсы, были «задействованы» маргинальные политические силы и индивидуальные политики с большим влиянием в Европе и США, были привлечены явные публичные структуры и экономические агенты, были организованы военизированные "народные волнения", и наконец, были введены военные формирования без знаков различия. Основной подход к организации всего этого персонала можно приблизительно охарактеризовать как «публично-частные партнерства», по образцу модели ПЧП, которая так популярна на Западе, за исключением злонамеренности сердцевины этой амбиции. Было бы ошибочно рассматривать российские атаки на Западе просто как действия сил специального назначения и вооруженных сил. Российская политика пользуется значительной внутренней поддержкой и для реализации общих целей были использованы большое число добровольцев из государственных структур и деловой среды, которые располагают собственными средствами. Конфликт с Украиной был всего лишь частью более масштабной атаки, и Россия полностью использовала слабости полицентрического мира.

Последствия этого наступления хорошо известны: НАТО получило новый смысл своего существования, что было закреплено на бумаге в документах саммита в Уэльсе, Соглашения об ассоциации Украины с ЕС подписаны и ждут ратификации, а российско-украинские отношения приобрели антагонистический характер. На Западе полюсы снова вошли в контакт, как во время Холодной войны. Многие области неопределенности сошлись в одном главном вопросе: выдержит ли Украина новую волну напряженности и какие компромиссы она готова сделать во имя своего самосохранения.

\section{Кризис на Украине: восточное измерение}

Украинский кризис имел определенные последствия для Восточного фронта: на Закавказье, в Центральной Азии и на Дальнем Востоке. Механизмы этих перемен многочисленны и различны, и их нелегко четко структурировать, как и сам полицентрический мир. Результат является комплексным и чреват еще большей напряженностью. Даже без злонамеренности с обеих сторон, концентрация напряжения в слабых местах полицентрического мира может спровоцировать инициирование формирования новых угроз.

Российский Кавказ был вовлечен в украинский кризис не на последнем месте и из-за факта, что основная ударная сила России на Украине была сформирована из так называемых национальных батальонов военных со- 
единений российского Южного оперативного командования. Эта группа понесла основные потери в живой силе с российской стороны на начальных этапах военных действий в Восточной Украине. Отношения между славянским населением России и обитателями Кавказа являются сложными. В последние годы они часто выливались в широкомасштабные столкновения на этнической основе. Российское руководство нашло путь для быстрого отклонения внутреннего конфликта, перенаправив его против славянского населения Украины. Однако, сейчас есть опасность, что конфликт снова вернется в Россию через украинскую границу, которую Россия сама сделала проницаемой. Важным аспектом является то, что в Чечне, которая в прошлом сама была сепаратистской республикой России, есть другой конфликт, который также может пересечь границу. На Украине Россия поддерживается так называемыми «кадыровскими» бойцами приверженцами Рамзана Кадырова, чеченского президента, который верен российскому руководству (благодаря щедрым финансовым инъекциям). В то же время, Украина поддерживается подразделениями, состоящими из чеченцев, которые все еще верны идеям бывшего президента Джохара Дудаева. Их меньше, но при определенных условиях они готовы напасть на свое отечество. В таком случае Кавказ взорвется в очередной раз.

В Закавказье есть три зоны с замороженными конфликтами: Южная Осетия, Абхазия и Нагорный Карабах. Политические процессы в Грузии исключают вероятность ухудшения отношений с Россией по поводу Южной Осетии и Абхазии в обозримом будущем. Однако, в Нагорном Карабахе эскалация конфликта возможна. Азербайджан занимает бескомпромиссную позицию: раньше или позже он должен вернуть себе суверенитет над Нагорным Карабахом. Экономическое и военное могущество Азербайджана постоянно увеличивается и уравновешивается только удобной линией обороны в Нагорном Карабахе, российской экономической помощью Армении и расположением российской военной базы на ее территории. Если Россия увязнет в украинском конфликте и окажется ослабленной международными санкциями, Азербайджан может воспользоваться возможностью разрешить проблему силой. Рецидив конфликта уже имел место в июле/августе 2014 года. До сих пор конфликт сдерживался дипломатической интервенцией России.

Цепь взаимоотношений продолжается от Нагорного Карабаха к Центральной Азии. Пытаясь провалить программу Восточного партнерства ЕС на всех фронтах (это был один из эпизодов в развитии кризиса вокруг Украины), в прошлом году Россия убедила Армению отказаться от ассоциации с ЕС во имя членства в Евразийском Экономическом Сообществе (ЕврАзЭС). Это создало дополнительные разногласия между Россией и Казахстаном. Казахстан, имеющий партнерские отношения с Азербайджаном, настаивает на том, чтобы в случае, если Армения присоединится к общему таможенному пространству, Нагорный Карабах не был бы вклю- 
чен в это пространство. Такие условия членства неприемлемы для Армении. Украинский кризис еще больше обострился из-за противоречий с ЕврАзЭС. Позиция Казахстана по вопросу дальнейшей интеграции с Россией стала более осторожной. Из Соглашения о создании ЕврАзЭС, которое было подписано в конце мая 2014 года, были убраны все ссылки на возможную политическую интеграцию. Казахстан совместно с Беларусью заблокировал попытки России ввести скоординированные торговые санкции против Украины. Более того, Казахстан открыто заявил, что не видит никаких экономических угроз для ЕврАзЭС, проистекающих от подписания Украиной Соглашений об ассоциации с ЕС, на существовании которых настаивала Россия.

К концу августа 2014 года ситуация ухудшилась еще больше в результате неуклюжего высказывания Путина о казахском президенте Нурсултане Назарбаеве: «Он создал государство на территории, на которой никогда не было государства. У казахов никогда не было государственности». ${ }^{12}$ До этого только российские политики невысокого уровня высказывали сомнения насчет казахской государственности. В результате получился большой скандал, поскольку Назарбаев сделал встречное заявление в отношение ЕврАзЭС: «Астана никогда не станет членом организаций, которые угрожают независимости Казахстана». ${ }^{13}$ В данном случае не так важны мотивы российских политиков, спровоцировавших Казахстан на фоне украинского кризиса - злонамеренность или небрежность, как сам факт, что напряженность в полицентрических связях достаточно высока, чтобы инициировать новый кризис.

Обострение ситуации в ЕврАзЭС из-за украинского кризиса в свою очередь оказало влияние на отношения с Шанхайской Организацией Сотрудничества (ШОС). Для России нейтралитет Китая в отношении украинского кризиса имел большое значение, поскольку для России он равнозначен прямой поддержке. Однако, деятельность ШОС в Центральной Азии увеличивает влияние Китая, что приводит к уменьшению влияния России. Китай обходит Россию как по торговому товарообороту, так и по инвестициям в данный регион. Кроме того, российское влияние связано с обострением разногласий с Узбекистаном, Кыргызстаном и Таджикистаном по так называемой гидроэнергетической проблеме. ${ }^{14}$ Более того, Туркменистан

12 «Путин ответил на вопрос о Казахстане», Новости Тенгри, 29 августа 2014, доступно на http://tengrinews.kz/sng/putin-otvetil-na-vopros-o-kazahstane-260975 (по состоянию на 31 августа 2014).

13 «Назарбаев заявил о возможном выхода Казахстана из Евразийского союза», Ак Жайик, 31 августа 2014, доступно на http://azh.kz/ru/news/view/22768 (по состоянию на 31 августа 2014).

14 Узбекистан воспринимает российские инвестиции в гидроэлектростанции в Кыргызстане, а также военную помощь Кыргызстану и Таджикистану как угрозу с точки зрения доступа к водным ресурсам и разрешения территориальных споров. 
практически вырвался из объятий России. Рост китайского влияния сейчас охватывает все страны регион, и до сих пор не был источником конфликтов.

Внимательное рассмотрение ситуации в Центральной Азии раскрывает два важных аспекта. Во-первых, сравнение торгового товарооборота разных стран региона с внешними игроками указывает на впечатляющие дисбалансы. К примеру, таможенная статистика Китая и Кыргызстана об одном и том же потоке товаров показывает для одной страны числа, которые в несколько раз выше, чем для другой. ${ }^{15}$ В последнее время эти различия несколько уменьшились, но все еще остаются слишком большими, чтобы объяснять их только методом вычисления. Статистические данные о товарообмене между Казахстаном и Россией так же указывают на разрыв более чем на 10\% за 2013 год (23.8 миллиардов долларов по статистике Казахстана ${ }^{16}$ и 26.5 миллиардов по российским данным). ${ }^{17}$ Это указывает на большой объем «серой» торговли китайскими товарами с Казахстаном и Россией через Кыргызстан. Планы Кыргызстана присоединиться к ЕврАзЭС только обостряют эту проблему.

Во-вторых, Россия сохраняет огромное влияние в определенных сферах в регионе благодаря его трудовым мигрантам. Их денежные переводы из России составляют значительную часть ВНП Таджикистана, Кыргызстана и Узбекистана. Эта зависимость имеет критически важное значение для Таджикистана: Россия может нанести большой вред его экономике просто запретив персональные денежные переводы (смотри Таблицу 1).

Это означает, что хотя Россия проигрывает Китаю в сфере торговли и инвестиций в Центральной Азии, у нее все еще есть возможности для негативного влияния: она может вызвать большой кризис в этом регионе, который обесценит растущее влияние Китая. У России нет конкретных причин действовать таким образом, но нет никаких сомнений в ее готовности, если на каком-то этапе Китай сочтет возможным использовать ослабление позиций России из-за украинского кризиса и западных санкций.

От Центральной Азии последствия украинского кризиса распространяются на российскую политику в отношение Ирана и Дальнего Востока. Однако, недавний прогресс на переговорах по ядерной программе, которые с ноября 2014 года обещали достижение долгосрочного соглашения и выход Ирана из изоляции, совпал с развитием украинского кризиса. Выход Ирана на рынки нефти и газа является прямой угрозой для России с учетом

15 Нурбек Токтакунов и др., Зеркальная таможенная статистика в КP: 20082012 годы (Бишкек, 2014).

16 «Внешнеторговый оборот Республики Кыргызстан», доступно на www.stat.gov.kz/ getlmg?id=ESTAT084715 (по состоянию на 31 августа 2014).

17 «Внешняя торговля российской федерации со странами СНГ», доступно на http://www.gks.ru/free_doc/new_site/vnesh-t/vnt-sng.xls (по состоянию на 31 августа 2014). 
Таблица 1. Оценка зависимости стран региона от России в отношение трудовой миграции.

\begin{tabular}{|c|c|c|c|c|c|c|}
\hline Страны & $\begin{array}{c}\text { Переводы } \\
\text { из России, в } \\
\text { миллионах } \\
\text { долларах } \\
\text { США }\end{array}$ & $\begin{array}{c}\% \\
\text { ВВП }\end{array}$ & $\begin{array}{c}\% \text { от рос- } \\
\text { сийского } \\
\text { ВВП }\end{array}$ & $\begin{array}{c}\text { Мигранты } \\
\text { в России, } \\
\text { в милли- } \\
\text { онах }\end{array}$ & $\begin{array}{c}\text { \% от } \\
\text { населе- } \\
\text { ния }\end{array}$ & $\begin{array}{c}\text { \% от } \\
\text { населе- } \\
\text { ния } \\
\text { России }\end{array}$ \\
\hline Узбекистан & 6633 & $11.68 \%$ & $0.32 \%$ & 2.58 & $8.53 \%$ & $1.80 \%$ \\
\hline Таджикистан & 4155 & $48.84 \%$ & $0.20 \%$ & 1.18 & $14.35 \%$ & $0.82 \%$ \\
\hline Кыргызстан & 2080 & $28.78 \%$ & $0.10 \%$ & 0.58 & $10.09 \%$ & $0.40 \%$ \\
\hline Казахстан & 455 & $0.20 \%$ & $0.02 \%$ & 0.55 & $3.24 \%$ & $0.38 \%$ \\
\hline Туркменистан & 40 & $0.10 \%$ & $0.00 \%$ & 0.23 & $4.39 \%$ & $0.16 \%$ \\
\hline
\end{tabular}

Замечание: Вычисления были сделаны по данным Центрального банка России, российской Федеральной Миграционной Службы и Всемирного банка. ВВП вычислен при нынешнем курсе доллара по статистическим данным за 2013 год.

критической зависимости ее экономики от мировых цен на энергоносители. Не имея основания или возможности помешать положительному развитию разговоров по иранской ядерной программе, Россия попыталась связать большие объемы иранской нефти с бартерными операциями. Тяжелые переговоры шли о годовом бартере 25 миллионов тонн иранской нефти на поставку российских товаров. Пока эти переговоры привели только к подписанию, в начале августа 2014, весьма скромного меморандума о годовом бартере в 2.5 миллионов тонн нефти. ${ }^{18}$ Таким образом, оказалось, что российские интересы на Украине связаны с ее интересами в иранской сфере.

На Дальнем Востоке украинский кризис так же привел к определенному перераспределению сил. Япония, у которой имеются территориальные споры с Россией, поддержала западные санкции. Южная Корея осталась нейтральной. Китай, как уже было упомянуто, оказал дискретную поддержку России, преследуя свои собственные цели: украинский конфликт ослабляет Россию и Запад, освобождая Китаю пространство для маневра. Северная Корея разделяет позицию России, хотя Россия вряд ли может ожидать большой пользы от этого, кроме как возможности оказывать отрицательное влияние на ситуацию путем эскалации конфликта вокруг ядерной и ракетной программ Северной Кореи.

18 «Иранский бартер. Россия и Иран подписали контракт о поставках нефти», BFM, 7 августа 2014, доступно на http://www.bfm.ru/news/268124 (по состоянию на 31 августа 2014). 
В общем, влияние украинского конфликта на Восток, похоже, не так сильно как на Европу. Однако, напряженность по целому ряду вопросов усилилась и с учетом определенного сочетания обстоятельств, могут появиться неожиданные усложнения. Этот анализ показывает множество слабых мест полицентрической системы отношений и вероятность того, что кризис может появиться в результате географически удаленного конфликта.

\section{Заключение}

Ускорение формирования новой системы международных отношений изза кризиса вокруг Украины, которую можно достаточно точно охарактеризовать как полицентрический мир, привело к появлению новых угроз и вызовов. Угрозы, которые можно разделить на традиционные (война с использованием оружия) и новые (неблагоприятные последствия технологического развития, глобализация и изменение климата) не исчезли. Однако, появилась еще одна опасность: отсутствие, или по крайней мере дефицит, глобального менеджмента; другой угрозой является возможность использовать преднамеренно слабые места полицентрического мира.

Украинский кризис показал, что диверсифицированная система отношений, которая способствует развитию, быстро может дегенерировать, порождая ситуацию времен Холодной войны. Оказывается, что такие обычные явления, как небольшие экономические и политические разногласия между центрами могущества, внутренние политические процессы в отдельных странах, перенастройка мировой финансовой системы и изменения цен на нефть могут привести к скоротечной концентрации противоречий, в данном случае вокруг Украины. В какой-то момент, Россия восприняла внутренние политические процессы в Украине как угрозу для своих интересов (такое восприятие было результатом внутренних процессов в самой России) и решила не просто защитить себя, следуя определенной концепции, но так же и использовать уязвимые места новой системы международных отношений с целью добиться широкомасштабного перераспределения могущества и влияния. Такая эскалация привела к возвращению к ситуации, которая похожа на биполярное противостояние в Берлинском, Корейском и Кубинском кризисе.

На Кавказе, в Центральной Азии и на Дальнем Востоке украинский кризис не привел к таким существенным переменам. Тем не менее, взаимосвязи в широком диапазоне стали объектом повышенной напряженности. По мере появления злонамеренных интересов, эта напряженность будет освобождаться порождая новые конфликты, которые могут не иметь очевидной связи с событиями на Украине.

В полицентрическом мире ускоряются как положительные, так и отрицательные процессы. Это означает, что локальная нестабильность быстро может привести к концентрации различных угроз. Даже если они тщательно изучены по отдельности и даже если в последние годы были 
найдены механизмы реакции на них, скорость с которой они появляются и степень в которой они проявляются в конкретный момент времени, сами по себе являются новой угрозой, которая уникальна для полицентрического мира. Все это можно охарактеризовать как неизбежная нестабильность развития.

Трудно дать какие-либо рекомендации относительно того, как надо действовать в ситуации, предшествующей завершению украинского кризиса - возможно первый из кризисов, полностью воплощающий сложности, описанные выше. Вполне вероятно, что Украина не только выживет, но и сохранит потенциал для развития как демократическая страна с быстро растущей экономикой. Это означает, что следует предпринять меры для сохранения устойчивого развития полицентрического мира и предотвращения скатывания в старые модели отношений.

\section{6 авторе}

Олексий Ицхак является заместителем директора днепропетровского регионального отделения Национального института стратегических исследований (НИСИ). До начала своей карьеры в НИСИ он работал в оборонной промышленности. Основной его обязанностью на настоящей должности является подготовка анализов по вопросам безопасности для государственных органов Украины. У него много публикаций по вопросам безопасности и международным отношениям в украинских профессиональных журналах и в периодической печати. 